\title{
Subsidence deformations of the foundations of hydraulic structures
}

\author{
Rustam Xujakulov ${ }^{1 *}, M$ Zaripov $^{1}$ and $U$ Normurodov $^{2}$ \\ ${ }^{1}$ Karshi Engineering and Economic Institute, Kashkadarya, Uzbekistan \\ ${ }^{2}$ Bukhara branch of Tashkent Institute of Irrigation and Agricultural Mechanization Engineers, \\ Bukhara, Uzbekistan
}

\begin{abstract}
One of the most important tasks in designing and constructing reclamation network structures on loess subsidence soils is to ensure their long-term trouble-free operation. The improvement of methods for the design of hydraulic structures on subsidence foundations requires further study of very complex physical processes occurring in the foundations of structures during their construction and operation. This is confirmed by the fact that even if all the requirements and recommendations of regulatory documents for the design of irrigation systems on subsiding soils are observed, the deformations of the foundations of structures often significantly exceed the calculated ones, which can cause a loss of serviceability of irrigation structures. This determines the need for further study peculiarities of interaction of irrigation structures with their subsidence bases. This article is devoted to this problem, in particular, to the study of the influence of stress redistribution in wetted subsidence foundations of hydraulic structures on the stressed state of their elements and the stress-strain state of loess subsidence foundations on the models of float bets of hydraulic structures in the Karshi steppe.
\end{abstract}

\section{Introduction}

Improving the reliability of hydraulic structures on collapsible soils can be achieved by improving their designs and improving soil properties foundations. This problem is devoted to the work of a number of scientists, for example, D.R. Bazarov, Mavlyanova D.A [1], M.R. Bakiev [3, 5], L.G. Balaev, V.P. Tsarev [6], M.A. Bandurin [7], G.N. Vinogradova [8], V.A. Volosukhin [9], V.A. Dokin [10], G.A. Zhakapbaeva [11], S.V. Zasov [12-13], S.V. Zasov, N.N. Frolov, R. Khuzhakulov [14], B.D.Kaufman, S.G. Shulman [15].

The results of studies of the operation of hydraulic structures on subsiding soils were reflected in the studies carried out by some Shakarna Saleh scientists [16], A.A. Kirillov [17], A.L. Mariupolskiy [18], D. Bazarov B. Uralov, B. Matyakubov, O. Vokhidov, F. Uljaev [19], R. Xujakulov, S. Zasov [20-21].

Field studies carried out by many scientists N. Maalem, I. Begmatov, K. Khasanov, S. Khidirov [22], S. Khidirov, B. Norkulov, Z. Ishankulov, P. Nurmatov, A. Gayur [23], Frolov N.N. [24] showed that the subsidence of loess soil is characterized by sharply

\footnotetext{
*Corresponding author: rustam868793@mail.ru
} 
uneven vertical deformations and horizontal displacements of the soil. These factors significantly complicate the working conditions of hydraulic structures on collapsible soils.

The specifics of the work of hydraulic structures CONSISTS that in the overwhelming majority of cases, their soil bases are moistened to the level of maximum water saturation. However, at first, after the commissioning of the GTS, the soil mass is moistened unevenly, which affects the nature of the interaction between the foundation and the structure.

Hydraulic structures and their subsidence foundations accept various loads and effects that differ in origin, duration, recurrence, etc. This article is devoted to the same issues.

\section{Methods}

Based on our studies, the results of which are presented in this work, a method is proposed for calculating the joint deformations of loess foundations and structures on them, having a foundation in the form of a rigid slab (for example, separate support for a trough network), in the absence of a drainage layer over the area of contact between the foundation and the ground.

Deformation of loess subsidence soils depends on two main factors - moisture and stress state of the massif. As noted earlier, the humidity and stress state of the loess foundations of commissioned hydraulic structures change over time. In this case, the moisture values corresponding to the maximum deformability of the soil do not coincide in time with the maximum stresses arising in the considered volume of soil.

\section{Results and Discussion}

In literature [13], the experimentally obtained values of stresses in the loess subsidence soils of the foundations of structures from the pressure transmitted by the structures are given, both maximum, arising on a given horizon, and corresponding to the period of their stabilization.

From the given values, when calculating the magnitude of the subsidence deformation, one should select the stresses corresponding to the conditions that determine the maximum deformability of the soil under study.

If the depth of the considered layer is $\mathrm{H}<0.5 \mathrm{R}$ fund or $\mathrm{H}<0.5 \mathrm{~B}$ fund; then we take following [13] $\sigma_{z}=P$, where $\mathrm{P}$ is the average pressure along the plane of contact between the soil and the foundation.

For the underlying layers, the soil deformability should be determined in two versions. In the first case, at critical soil moisture, taking into account the stress concentration that occurs during the passage of the moisture front through the horizon; in the second - at humidity and voltages corresponding to the period of their stabilization.

When carrying out compression tests, the pressure on the soil sample should be assigned following the formula:

$$
P_{o}=\alpha P+0.01 \rho h, \mathrm{MPa}
$$

where $\alpha$ is coefficient taken according to Table 2.4 of this work; $P$ is average pressure under the foot of the foundation, MPa; $\rho$ is soil density, $\mathrm{t} / \mathrm{m}^{3} ; h$ is the depth of the location of the middle of the layer under consideration.

The degree of subsidence of the soil at critical humidity corresponding to the period of stress concentration in it is expressed by the value of the relative subsidence in accordfollowingula proposed in the instructions for the design of irrigation systems on subsidence soils: 


$$
\varepsilon_{s l(\kappa)}=\frac{\omega_{k}-\omega}{\omega_{\max }-\omega} \varepsilon_{s l}^{\prime}
$$

Where $\omega, \omega_{k}, \omega_{\max }$ are respectively, natural, critical and maximum possible soil moisture in fractions of a unit;

$\varepsilon_{s l}^{\prime}$ is the value of the relative subsidence of the soil determined by the traditional method but taking into account the stress concentration on the horizon.

It is advisable to calculate the amount of subsidence deformation according to the formula:

$$
S_{s e}=K \sum_{1}^{n} \varepsilon_{s l i}^{\prime} h_{\mathbf{i}} m_{\mathbf{i}}
$$

where $\varepsilon_{s l i}$ is the greater of the values of the relative subsidence of a separate soil layer in two options under consideration, $h_{i}$ is the thickness of the calculated soil layer; $m_{i}$ is coefficient of working conditions, taken according to table 2 .

The previously stated results of studies of the operation of elements of tubular hydraulic structures on subsiding soils showed that their stress-strain state is transformed in the process of soaking the foundations of structures. The values of the stresses arising in this case in the diaphragm body can significantly exceed those obtained as a result of calculations using traditional methods, which are reflected in the regulatory documents.

Based on the studies carried out on the operation of flatheads (diaphragms) of hydraulic structures, we propose design schemes that take into account the conditions of their operation. The mentioned schemes are summarized in Table 1.

Four main options are considered.

1. In the event that the pressure transmitted by the diaphragm to the base is insufficient to cause subsidence deformation in it, then the operating conditions of the diaphragm are similar to those in structures installed on non-subsiding soils. The calculation of the diaphragm, in this case, should be carried out according to the generally accepted method, based on the hypothesis, it agrees with the experimental data (Figure 1, "v").

2. In the case of partial wetting of the linear distribution of the response reaction, which is quite accurate for the soil under the middle part of the diaphragm, its design scheme takes the form presented in paragraph 2 of table 1 following the proposed scheme, the pressure at the contact of the diaphragm with the moistened soil should be taken equal to $P_{\text {нач. }}$. The pressure at the contact of the diaphragm with the unmoistened part of its base increases accordingly and is distributed evenly. Force $\mathrm{N}$ can act on the lateral faces of the diaphragm in case of its operation on soils of the second type due to subsidence. The maximum value of this force is equal to the possible value of the transverse (shearing) force Qmax in the soil, pressing on the side face of the diaphragm. The Qmax value is calculated by the formula, with a known value of the specific cohesion of the soil of natural moisture[13].

The proposed design scheme will be valid when the values of "a" equal or exceed those obtained when calculated by the formula:

$$
Q_{1}+0.5 Q_{2}-P_{n a c h} b l_{1}-0.5 P_{n a c h} b l_{2}=\frac{a b c}{\operatorname{tg} \beta}+\frac{a^{2} \operatorname{ctg} \alpha}{\operatorname{tg}^{2} \beta}
$$

3. If the value of the parameter "a" is less than that obtained by calculation, then Scheme 3 in Table 1 should be taken as the calculated one.

Following this scheme, the soil along the entire length of contact with the lower edge of the diaphragm perceives pressure equal to the initial subsidence pressure. In this regard, a 
significant part of the pressure of the mass of the diaphragm is absorbed by the water pipe. The diaphragm hangs on the pipe.

The diaphragm operation, corresponding to the considered scheme, occurs before the onset of deformations of soil subsidence under its own weight. In this regard, the bulk of soil on the lateral faces of the diaphragm, as a small value and going into the reserve, is neglected.

The proposed scheme should also be used when soil is moistened along the entire length of contact with the lower edge of the diaphragm $(\mathrm{a}=0)$.

Design scheme 4 in Table 1 is proposed for the case of the diaphragm operating on soils of the second type in terms of subsidence; sometimes, the possible bulk on the lateral faces of the diaphragm is sufficient to fix it.

To determine the time of soaking a homogeneous stratum of the loess massif through the pits arranged at the construction site of the hydraulic structure, it is proposed to use the experimental-graphic method.

To do this, on the soil site of the planned construction, an experimental soil soaking should be carried out through a pit with a diameter

$$
d_{k}=n_{1} \sqrt{F_{k}}
$$

Where $n_{1}=0.11-0.12, F_{k}$ is area of the water mirror of the designed compact (round or square) pit.

Table 1. Design diagrams of tubular structures, conditions for their use

\begin{tabular}{|c|c|c|c|}
\hline № & Calculation scheme & $\begin{array}{c}\text { Calculation } \\
\text { method }\end{array}$ & Terms of use \\
\hline 1 & 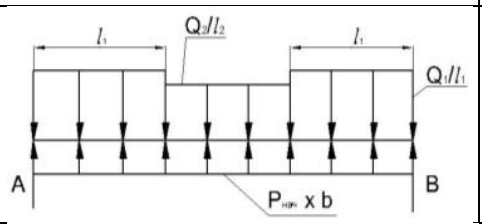 & $\begin{array}{l}\text { The } \\
\text { hypothesis of } \\
\text { the linear } \\
\text { distribution of } \\
\text { the response } \\
\text { reaction }\end{array}$ & $\begin{array}{l}\text { a) the average pressure transmitted } \\
\text { by the diaphragm to the ground is } \\
\text { significantly less than the initial } \\
\text { subsidence; } \\
\text { b) the diaphragm rests on the soil } \\
\text { of natural moisture }\end{array}$ \\
\hline 2 & 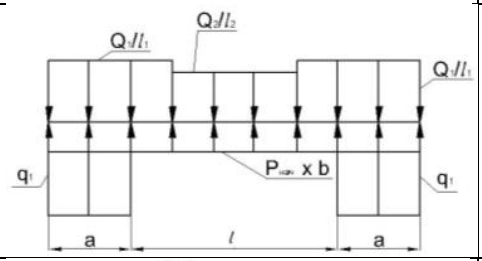 & Formula (4.6) & $\begin{array}{l}P_{a v} \geq P_{\text {nach, }} \text { the base of the } \\
\text { diaphragm, is partially moistened, } \\
\text { the load on the wedges of the } \\
\text { unmoistened soil does not exceed } \\
\text { the permissible (in accordance with } \\
\S 4.2 \text { ) }\end{array}$ \\
\hline 3 & ${ }_{q_{0}}$ & Formula (4.2) & $\begin{array}{l}P_{a v} \geq P_{\text {nach, }} \text { the base of the } \\
\text { diaphragm, is completely } \\
\text { moistened. } \\
P_{a v} \geq P_{\text {nach, }} \text { the base of the } \\
\text { diaphragm, is partially moistened, } \\
\text { the load on the wedges of } \\
\text { unmoistened soil predetermines } \\
\text { their permissible cleavage } \\
\text { (according to } \S 4.2 \text { ) }\end{array}$ \\
\hline 4 & $\underset{\substack{N^{*} f_{C}}, 1,1,1,1,}{N}$ & $\begin{array}{c}\text { According to } \\
\text { the materials } \S \\
4.4\end{array}$ & $\begin{array}{l}\text { The scheme is correct only in soils } \\
\text { of type II due to subsidence, in the } \\
\text { case of soil piling on the lateral } \\
\text { edges of the diaphragm, sufficient } \\
\text { for its fixation } P_{a v} \geq P_{\text {nach }}\end{array}$ \\
\hline
\end{tabular}


If the required pit diameter by calculation does not exceed $25 \mathrm{~cm}$, then we take $d_{k}=25$ $\mathrm{cm}$.

The required flow rate of water supplied to the test pit should be determined by the formula

$$
Q=\frac{F_{k}}{K_{n}}
$$

where $K_{n}=6.5 \mathrm{~m}^{2}$ hour / liter is conversion factor.

In the case of using the proposed device [12] during the experimental soaking, the water consumption should be halved.

Determination of the capacity of the wetted part of the soil massif at the base of the projected excavation after a given time is carried out according to the formula:

$$
H_{3 t}=K_{u} h_{3 t}
$$

Where $h_{3 t}$ is the depth of the moistening zone at the base of the test pit in the time after the start of soaking;

$K_{u}$ is the drive factor, determined following Figure 3.14 from work.

After obtaining several values of $\mathrm{H} 3$ for different values of $t$, a graph $\mathrm{H} 3=\mathrm{f}(\mathrm{t})$ should be plotted, which makes it possible to determine the time for soaking the array to a given depth.

If in the pit, through which it is planned to soak the soil massif, there is a structure that transfers pressure $\mathrm{P}$ to the base and has a foundation in the form of a circle or square with an area of about $1 \mathrm{~m}^{2}$ (for example, support for a trough network), then the graphs shown on fig. $3.14 \mathrm{~b}, \mathrm{v}, \mathrm{g}$ at work [13]. In this case, during the experiment, a stamp with a diameter $d_{p}=25 \mathrm{~cm}$ and transmitting the appropriate pressure to the ground should be installed in the pit.

If the pressure P has a value different from those for which the graphs in Figure 3.14, the value of $\mathrm{Ku}$ is determined by interpolation.

In cases where the soaking of the soil mass is supposed to be carried out through rectangular pits with a side ratio $1 / b \neq 1$ or through a section of the channel, relying on the research results given in this work, it is possible to take using the graphs) the conditional area of the pit determined by the formula:

$$
F_{u s l}=K_{f} B^{2}
$$

Where $K_{f}$ is the shape factor of the pit, taken from the graph 3.9 [13].

Further, the calculation of the time of moistening the soil mass is carried out in the manner described above.

Suppose it is necessary to determine the optimal dimensions of the pit for wetting the mass of loess soil with a thickness of $\mathrm{H}$ in time $\mathrm{t}$. In that case, a series of experiments should be carried out on the studied area using the device[12], consisting of three or four soaks at different rates of water supply $Q$ into the pits of corresponding diameters $d_{k}$. Then, based on experimental data, using the graphs shown in Figure 3.14 in the work [13] in the axes $H_{3}$ and $F_{k}$ it is necessary to construct a curve $H_{3}=f\left(F_{k}\right)$ for a given value of $\mathrm{t}$. The Fc value corresponding to the given thickness of the soil layer will be the required area of the projected excavation.

The calculated and recorded values of the shrinkage deformation of the chute support at PK $31+50$ of the tail part of the distributor 3-X of the "Samarkand" massif, transmitting the design pressure $\mathrm{P}=0.11 \mathrm{MPa}$ to the ground and having dimensions in the plan of $1.5 \mathrm{x}$ $1.5 \mathrm{~m}$, were compared.

The depth of the foundation base is $1.5 \mathrm{~m}$. 
Characteristics of loess base soils:

Natural moisture $\omega=(0.08-0.10)$

Porosity $\mathrm{n}=46 \%$

Density of dry soil $\rho_{d}=1.34 \mathrm{~g} / \mathrm{cm}^{2}$

Density of soil particles $\rho_{s}=2.48 \mathrm{~g} / \mathrm{cm}^{3}$

Wetting of the base soil is caused by the leakage of the tray on the support.

An array of moistening to a depth of 3.3 meters (Figure 1). The average soil moisture within the moisture zone is $\omega=0.22$, which is typical for cases of soil moisture due to the formation of a leak in the trough network.

The average density of the moist soil can be determined by the formula

$$
\rho_{u v}=\rho_{d}(1+\omega)=1.34(1+0.22)=1.635 \mathrm{~g} / \mathrm{cm}^{3}
$$

The curves of the relative subsidence for different values of the soil moisture content of the base of the tray support are shown in Figure 2.

Calculations to determine the vertical stresses at the base of the support are summarized in Table 2. the given values of $\sigma_{1}$ correspond to the recommendations of KMK 2.02.02-98 $\sigma_{2}$ and $\sigma_{3}$ for the cases of stabilized stresses and bearing of the layer on unmoistened soil, respectively.

\begin{tabular}{|c|c|c|c|c|c|}
\hline & & & \\
\hline
\end{tabular}




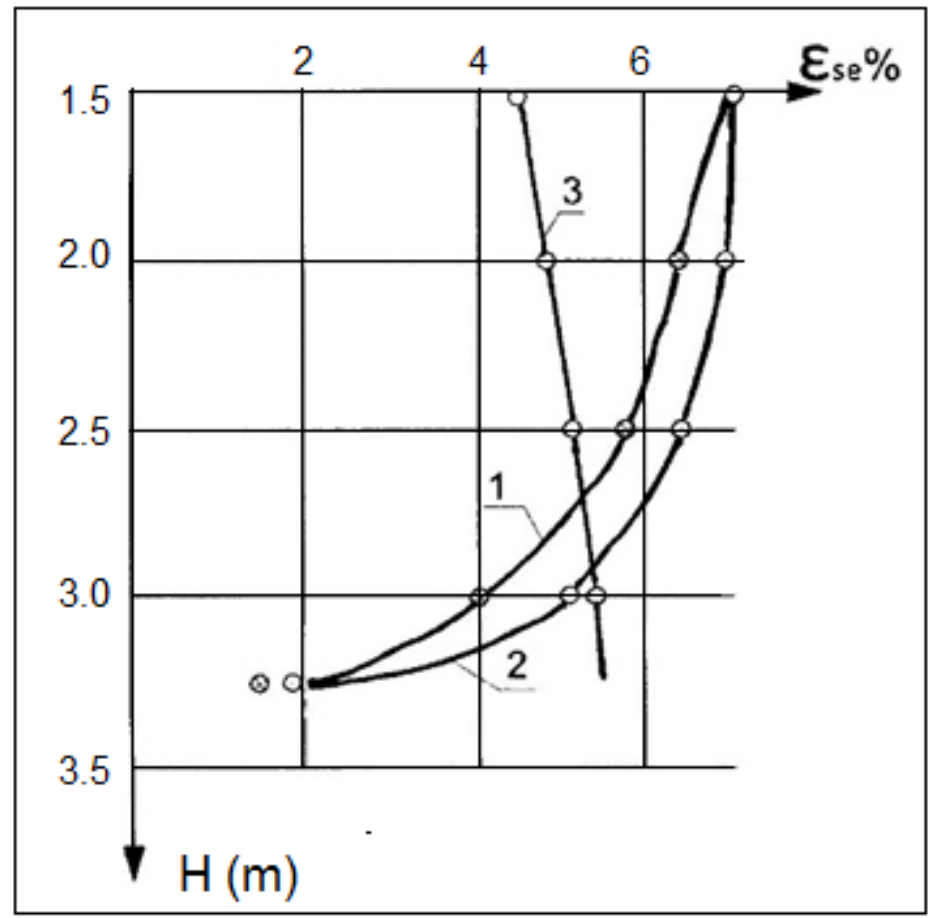

Fig. 3. Graphs of changes in the relative subsidence of soil

Ese1, Ese2, Ese 3 at voltages determined by:

1 - following the instructions of KMK2.02.02-98

2- for the case of voltage stabilization;

3- taking into account their concentration when the soil reaches critical moisture content.

The obtained values of the relative subsidence along the depth of the base of the strut support are shown in Figure 3. Curves 1, 2, 3 are plotted following the values of stresses in the soil $\sigma_{1}, \sigma_{2}$, and $\sigma_{3}$ given in Table 2 . When constructing curves 1 and 2 , the relative subsidence of the soil was determined following its moisture content at the considered horizon and the moment of attenuation of the process of subsidence of the massif (Fig. 1). When constructing curve 3 , it was taken into account that the time of stress concentration at each individual horizon corresponds to soil moisture equal to the critical $\omega_{c r}$. For the considered soils $\omega_{c r}=(0.18-0.19)$.

As can be seen from Figure 3 the deformability of the soil, which occurs during the period of passage of the moisture front through it, is less than with stabilized stresses only at a depth of 2.9 meters from the soil surface. This makes it necessary to consider the stress concentration arising in the soil of critical moisture when passing through the wetting front when predicting the subsidence of a part of the massif lying at a greater depth.

The calculation of the deformation of the subsidence of the loess base was carried out by the recommended VSN ("Instructions for the design of irrigation systems on subsidence soils").

\section{Conclusions}

The above makes it possible to draw the following conclusions:

- the results of determining the values of the layer-by-layer deformations of the base of the support strut are summarized in Table 3. It can be seen from the table that the value of 
subsidence soil deformation calculated according to the method proposed in this work is significantly higher than that calculated following the instructions of the current regulatory documents and is much closer to that obtained during field measurements;

- Table 4 shows the results of the calculated and actual values of the deformation of the subsidence of the bases of round dies (zone of the distributor 4-X) and the support of the chute network installed in the tail part of the distributor 3-X. When calculating deformations, the real distribution of moisture in the soil mass was taken into account;

- it follows from Table 4 that the experimental data for determining the amount of Ssl drawdown are significantly better consistent with those determined by the method described above $\left(S_{s l}^{0}\right)$ than with those calculated by the BCH $\left(S_{s l}^{l}\right)$. Indeed, the mean deviation of $S^{0}{ }_{s l} / S_{s l}$ is 1.05 , while $S^{0}{ }_{s l} / S_{s l}=0.81$. The standard deviation of the $S^{0}{ }_{s l}$ estimate from the measured value is $8.4 \%$, and $S_{s l}{ }^{l}$ is $19 \%$. The value of $8.4 \%$ can be considered as an error in calculating $S_{s l}$ by our proposed method;

Table 2. Stresses on the depth of the loess base of the rack tray support

\begin{tabular}{|c|c|c|c|c|c|c|c|c|}
\hline \multirow{2}{*}{$\begin{array}{l}\text { Depth } \\
\text { from } \\
\text { the } \\
\text { ground } \\
\text { surface } \\
\text { (M) }\end{array}$} & \multirow{2}{*}{$\begin{array}{l}\text { Pressure } \\
\text { from the } \\
\text { moisten } \\
\text { ed } \\
\text { soil } \\
\text { surface } \\
(\mathrm{MPa}))\end{array}$} & \multirow{2}{*}{$\begin{array}{l}\text { Distance } \\
\text { from the } \\
\text { base of } \\
\text { the } \\
\text { foundatio } \\
\mathrm{n} \text { to the } \\
\text { design } \\
\text { plane (m) }\end{array}$} & \multicolumn{3}{|c|}{ Additional pressure $(\mathrm{MPa})$} & \multicolumn{3}{|c|}{ Total pressure $(\mathrm{MPa})$} \\
\hline & & & $\begin{array}{l}\text { Accordi } \\
\text { ng to the } \\
\text { standard }\end{array}$ & $\begin{array}{c}\text { For the } \\
\text { case of } \\
\text { stabilized } \\
\text { voltages }\end{array}$ & $\begin{array}{l}\text { For the } \\
\text { case of } \\
\text { resting } \\
\text { the layer } \\
\text { on a wet } \\
\text { ground }\end{array}$ & $\mathrm{G}_{1}$ & $\mathrm{G}_{2}$ & $\mathrm{G}_{3}$ \\
\hline 0 & 0 & - & - & - & - & 0 & 0 & 0 \\
\hline 1.5 & 0.025 & 0 & 0.110 & 0.110 & 0.110 & 0.135 & 0.135 & 0.135 \\
\hline 2.0 & 0.032 & 0.5 & 0.107 & 0.109 & 0.110 & 0.133 & 0.141 & 0.142 \\
\hline 2.5 & 0.041 & 1.0 & 0.094 & 0.107 & 0.109 & 0.135 & 0.148 & 0.150 \\
\hline 3.0 & 0.049 & 1.5 & 0.077 & 0.102 & 0.107 & 0.126 & 0.151 & 0.156 \\
\hline 3.5 & 0.057 & 2.0 & 0.062 & 0.092 & 0.107 & 0.119 & 0.149 & 0.157 \\
\hline
\end{tabular}

Table 3. Layer-by-layer deformations of the moistened base of the tray network support

\begin{tabular}{|c|c|c|c|c|}
\hline \multirow{2}{*}{$\begin{array}{l}\text { Number } \\
\text { of layers }\end{array}$} & \multirow{2}{*}{$\begin{array}{l}\text { Layer } \\
\text { boundaries } \\
\text { by depth }\end{array}$} & \multicolumn{3}{|c|}{$\mathrm{S}_{\mathrm{sl}(\mathrm{cm})}$} \\
\hline & & $\begin{array}{l}\text { According to } \\
\text { the standard }\end{array}$ & $\begin{array}{l}\text { According to the } \\
\text { proposed method }\end{array}$ & $\begin{array}{l}\text { According to } \\
\text { experimental data }\end{array}$ \\
\hline 1 & $1.5-2.0$ & 5.13 & 5.31 & 5.30 \\
\hline 2 & $2.0-2.5$ & 4.62 & 5.16 & 5.00 \\
\hline 3 & $2.5-2.9$ & 3.16 & 3.63 & 3.50 \\
\hline 4 & $2.9-3.25$ & 1.62 & 2.94 & 2.70 \\
\hline & Total & 14.53 & 17.04 & 16.50 \\
\hline
\end{tabular}

Let's check the possibility that the deviation of $S_{s l}^{0} / S_{s l}$ from one is random. According to the Student's method, the tp statistic for this ratio is equal to, which, for the number of values $\mathrm{n}$ $=12$, corresponds to the probability $P=0.95$. This suggests that there is no statistically distinguishable deviation of $S_{s l}^{0} / S_{s l}$ from one;

These results indicate the need to take into account the stress state of the wetted loess bases of hydraulic structures when calculating them for the first and second groups of limit states. 
Table 4. Subsidence of the bases of experimental structures

\begin{tabular}{|c|c|c|c|c|c|c|}
\hline \multirow{2}{*}{ № } & \multirow{2}{*}{ Names } & \multirow{2}{*}{$\begin{array}{c}\text { The } \\
\text { average } \\
\text { pressure } \\
\text { on the } \\
\text { sole, } \mathrm{MPa}\end{array}$} & \multirow{2}{*}{$\begin{array}{l}\text { Wet zone } \\
\text { depth, m }\end{array}$} & \multirow{2}{*}{$\begin{array}{l}\text { Actual size of } \\
\text { subsidence } \\
\mathrm{cm}\end{array}$} & \multicolumn{2}{|c|}{$\begin{array}{l}\text { Estimated value of the } \\
\text { drawdown, cm }\end{array}$} \\
\hline & & & & & $\begin{array}{l}\text { According } \\
\text { to the } \\
\text { standard }\end{array}$ & $\begin{array}{l}\text { According to } \\
\text { the proposed } \\
\text { method }\end{array}$ \\
\hline 1 & stamp D $=1.12$ & 0.05 & 2.7 & 9.0 & 6.90 & 10.84 \\
\hline 2 & stamp D $=1.12$ & 0.05 & 3.71 & 12.8 & 8.68 & 12.31 \\
\hline 3 & stamp D $=1.12$ & 0.05 & 5.2 & 16.5 & 11.68 & 18.17 \\
\hline 4 & stamp D $=1.12$ & 0.10 & 2.3 & 15.1 & 11.68 & 14.90 \\
\hline 5 & stamp D = 1.12 & 0.10 & 3.50 & 17.1 & 13.57 & 17.81 \\
\hline 6 & stamp D $=1.12$ & 0.10 & 4.7 & 24.8 & 17.98 & 26.72 \\
\hline 7 & stamp D $=1.12$ & 0.15 & 2.2 & 18.8 & 16.66 & 20.00 \\
\hline 8 & stamp D $=1.12$ & 0.15 & 3.35 & 23.9 & 19.59 & 21.90 \\
\hline 9 & stamp D $=1.12$ & 0.15 & 4.7 & 28.2 & 24.47 & 31.17 \\
\hline 10 & $\operatorname{stamp~D}=1.12$ & 0.20 & 1.8 & 20.9 & 18.5 & 22.02 \\
\hline 11 & stamp D $=1.12$ & 0.20 & 4.6 & 32.7 & 28.98 & 34.10 \\
\hline 12 & $\begin{array}{c}\text { Tray network } \\
\text { support } 1.5 \times 1.5 \mathrm{~m}\end{array}$ & 0.11 & 3.3 & 16.5 & 14.53 & 17.04 \\
\hline
\end{tabular}

\section{References}

1. Bazarov, D.R., Mavlyanova, D.A. Numerical studies of long-wave processes in the reaches of hydrosystems and reservoirs. Magazine of Civil Engineering, 87(3), pp. 123-135, (2019), DOI:10.18720/MCE.87.10.

2. Xujakulov R. Stresses in subsidence bases of flutbet models under the moisturizing conditions, IOP Conf. Series: Materials Science and Engineering 1030, (2021) doi:10.1088/1757-899X/1030/1/012138

3. Bakiev M.R. Criteria for the reliability of the Ugam irrigation system. International scientific and practical conference "Improving the efficiency, reliability and safety of hydraulic structures,1, pp. 23-28, Tashkent, (2018)

4. R. Xujakulov R. M Rahmatov, E Nabiev and M Zaripov. Determination of calculating stresses on the depth of loess grounds of hydraulic structures, IOP Conf. Series: Materials Science and Engineering 1030 (2021), doi:10.1088/1757899X/1030/1/0121331

5. Bakiev M.R. Analysis of the problems of reliable and safe operation of earth dams of water storage facilities, In Sat. international scientific and practical conference "Improving the efficiency, reliability and safety of hydraulic structures, pp. 16-22, (2018)

6. Balaev L.G., Tsarev V.P. Loess rocks of the central and eastern Ciscaucasia. p. 234, Moscow, Nauka, (1964)

7. Bandurin M.A. Diagnostics of the technical state and assessment of the residual resource of the operability of water-conducting structures of irrigation systems. Step Doctorate in Engineering Sciences, p. 285, Moscow, (2017)

8. Vinogradova G.N. Investigations of the compaction of subsiding soils by preliminary soaking in irrigation construction, p. 22, Moscow, (1968)

9. Volosukhin V.A. Factors determining the safety of hydraulic structures for water management purposes, Science and security, № 3 (12), pp.7-8, (2014)

10. Dokin V.A. Study of the joint work of irrigation structures and their subsidence 
foundations, composed of loess soils, p. 176, Moscow, (1980)

11. Zhakapbaeva G.A. Improvement of design techniques for irrigation systems on collapsibl soils based on joint ultimate deformations, p. 20, (2001)

12. Zasov S.V., Frolov N.N. Study of the stress-strain state of loess subsidence foundations of structures, In the book: Hydraulic structures, foundations and foundations, engineering structures, pp. 36-43 Moscow, (1982)

13. Zasov S.V. Interaction of hydraulic structures of irrigation systems with subsidence foundations, p. 20, Moscow, (1986)

14. Zasov S.V., Khuzhakulov R. Improving the operational reliability and safety of hydraulic structures of irrigation systems on subsidence soils, p. 162, Tashkent, (2019)

15. Zasov S.V., Frolov N.N., Khuzhakulov R. Features of the stress-strain state of loess subsidence foundations of the NIITZI Agroprom structure of the Ministry of Agriculture of the Russian Federation, No.-68, VS-96, Dep. M., p. 6, (1996)

16. Kaufman B.D., Shulman S.G. Methods of the uncertain factors account in a reliability assessment of a "construction-foundation" system at seismic impacts. Proc. of 4th Annual International Conference on Civil Engineering, Athens, Greece, (2014)

17. Shakarna S. Assessment of the reliability of hydraulic structures based on a systematic approach taking into account seismic conditions, p. 25, Samara, (2012)

18. Kirillov A.A. Features of moisture transfer in thick strata of strongly subsiding soils during their preliminary soaking, In the book: New methods of construction and hydraulics of hydraulic structures, Moscow VNIIGIM. Issue 4, pp. 136-141, (1978)

19. Mariupolskiy A.L. Investigation of the operation of irrigation structures on collapsible soils and improvement of methods for their design, p. 24, Moscow, (1975)

20. Bazarov D., Uralov B., Matyakubov B., Vokhidov O., Uljaev F., Akhmadi M. The effects of morphometric elements of the channel on hydraulic resistance of machine channels of pumping stations, IOP Conference Series: Materials Science and Engineering, 869(7), (2020) DOI:10.1088/1757-899X/869/7/072015.

21. Rustam X., Sergey Z. Studying of Deformation Properties of the Additive Bases with the Help utilizing Special Installation.International Journal of Advanced Research in Science, Engineering and Technology, 6,(5), (2019)

22. Rustam X., Zasov S. Research of the Diaphragm of the Tubular Hydro construction from Action of own Weight, International Journal of Advanced Research in Science, Engineering and Technology, 6(5), (2019)

23. Khidirov S., Norkulov B., Ishankulov Z., Nurmatov P., Gayur A. Linked pools culverts facilities, IOP Conference Series: Materials Science and Engineering. 883(1), (2020), doi:10.1088/1757-899X/883/1/012004

24. Frolov N.N. Design of foundations and foundations of hydro-reclamation structures, pp. 111-138, Moscow, (1967) 